\title{
Shifting education's philosophical imaginaries: relations, affects, bodies, materialities
}

\author{
Sharon Todd ${ }^{a}$, Rachel Jones ${ }^{b}$ and Aislinn O'Donnell ${ }^{c}$ \\ ${ }^{a}$ Department of Education, Maynooth University, Ireland; ${ }^{b}$ Department of Philosophy, George Mason \\ University, USA; ${ }^{C}$ Faculty of Education, (MIC) University of Limerick, Ireland
}

As Michèle Le Doeuff pointed out in her classic feminist work, The Philosophical Imaginary, images function in philosophical writing to enact certain political and theoretical possibilities and limitations. She draws our attention to the relationship between images and concepts throughout the history of philosophy, and philosophy's forgetting and occlusion of its own imaginaries. We wonder with Le Doeuff about the image that philosophy gives to itself of what it is to do philosophy. So too we wonder about the images that orient and inflect both educational practice and research. What images do educational researchers give to themselves of education, the practice of education and of research in education? This issue examines the ways in which diverse educational imaginaries operate. It thinks from and with recent feminist work in both philosophy and education. Feminist educational concerns have often focused on images of relationality, sex/gender differences and queer subjectivities. The essays presented here build on this by examining the ways in which recent feminist and queer theory can both re-inflect such images and generate new ones in order to reframe our attention to what matters in educational theory and practice. The issue is informed by feminist philosophy's recent (re)turns to materialism, embodiment and affect and its renewed engagement with phenomenology, a process that has involved a pronounced shift away from the images of social construction that had informed much feminist work since the 1970s. Such moves contest the privileging of either realism or social construction in educational research by opening up different conceptions of material and relational ontologies that do not fit neatly into either side of that binary, and that can grapple with the complexities of educational research and practice. What also matters here is finding ways both to theorise practice and to practise theory without reducing practice to either 'tips of the trade' exchanged amongst practitioners or the mere application of a set of already worked out ideas.

This special issue on shifting education's philosophical imaginaries is therefore an inquiry into how and to what extent those feminist approaches that shift educational practices, theories and structures are (or could be) in turn linked to recent shifts within feminist philosophical thought. We are interested in how philosophical developments can inform a re-imagining of educational concerns, and how educational imaginaries may also open up a different set of questions for contemporary feminist philosophies. We are not concerned with finding strategies to 'import' new philosophical ideas into educational theory and practice, or with simply reading such ideas as something 'external' to the work we do in

CONTACT Aislinn O'Donnell aislinnjodonnell@gmail.com 
education. Rather, our aim is to open up a conversation between educational theory and this new body of feminist philosophical scholarship in a manner that reveals their co-implication, particularly when it comes to conceiving of how to theorise what is done in the name of education, what limits and transformative possibilities lie within the educational project, and the ways in which ideas can be enacted in pedagogical settings. We argue that feminist philosophies are helpful for generating new educational imaginaries beyond those inherited from the Western philosophical tradition and ask: How and where are those more 'traditional' imaginaries, with their emphasis on particular images of both education and the (teaching/learning) subject, still embedded in educational settings, and with what effects? How might educational practice give rise to new philosophical imaginaries that would take the complexity of relational contexts, such as classrooms, seriously? And how might pedagogical practices be sparked and fed by ideas that are drawn from contemporary feminist and queer theory, in particular those that put contemporary philosophies of affect, materiality, the animal and the post-human to work in feminist and queer ways?

In Imaginary Bodies, Gatens writes,

Specific peoples, specific kinds of body-grouping, are going to produce quite specific 'ways of being'. 'However,' this is not to imply that values, because they are constructed in specific historical and social contexts, are therefore groundless or nonbinding...[s]uch values are thoroughly 'grounded' in the particular needs, desires, struggles, histories and institutions of particular communities. $(1996,102)$

There is nothing 'natural' about the practices, images, values and ideas of a social body. Just as each of us, as embodied subjectivities, can map the associative trajectories of our lives, and the sets of wider relations and contingent encounters that have led to the genesis or formation of our individual and particular characters, mapping the geneses or histories of social bodies and institutions, such as schools, can show how their social and educational imaginaries have been constituted.

The approach taken by the essays in this special issue does not deny the materiality (or perhaps better, the materialities) of our present condition and current practices: on the contrary, as they show, understanding the genesis of both individuals and institutions means understanding the diverse material and affective processes through which bodies of all kinds are constituted and sustained. However, it does open up the possibility for transformation through both a critical understanding of the constructed nature of those affiliations, and the development of creative practices that allow affects to be rerouted, relations to be re-worked, and bodies to be undone and re-composed. As Gatens writes,

Our embodied history cannot be thrown off as if it were a coat that one has donned only involuntarily in the first place. Whether we like it or not, in so far as our values and our 'ways of being' are embodied they cannot be wished away or dismissed by a pure act of will. (1996, 105)

Although much contemporary educational scholarship draws on new directions of feminist philosophy, ${ }^{1}$ very little of it is devoted to examining the image that education gives to itself of what it is. Yet such images play a crucial role both in constituting the parameters of educational practice and in exposing where its blind spots may lie. An approach centred on the critical exploration of such images (and the generation of potential counter-images) 
is different from the kind of conceptual analysis that centres upon an examination of presuppositions and assumptions. We suggest that whilst new feminist philosophies and queer theories are increasingly used as frameworks for analysis, and as a basis for much needed critique of current educational policy, these new theoretical frames have not been seen as themselves embedded in imaginaries that are also in need of critical appraisal from the very particular point of view that educationalists can offer. Images of becoming, life, affect, bodies and materiality/matter-ing - to mention just some of the images that permeate the kinds of recent theorising engaged in this special issue - offer productive resources for re-imagining both pedagogical processes and their theorising. An educational perspective returns these images to the specificity of lived, pedagogical contexts in ways that allow us to sift through their limits and potential, even as these images bring new resources to feminist theorising about education.

In the debates about agency, transformation and ontology that this new philosophical literature addresses and provokes, there is a danger of losing sight of the insights of practitioners about the 'messy' world of classrooms, as well as of the resources already available within established feminist approaches to subjectivity, relationality and sexed embodiment. The 'new materialisms' are not entirely 'new', though they do re-inflect and at times re-direct long-standing feminist concerns with bodies and materiality in significant ways via a sustained critique of social constructionism and a generative re-appraisal of matter, nature, agency and the (post-)human. By staging an encounter between feminist educational theory and practice on the one hand, and new directions in feminist philosophy and queer theory on the other, one of the aims of this issue is to allow generative synergies and productive tensions to emerge in ways that cut across different moments of feminist theorising. In so doing, we hope to further critical debate, and provide richer and more nuanced approaches to reflection on the educational encounter - whether it takes place within or outside of the classroom, between irreducibly different human beings, or between humans and other animals.

Another underlying concern of this special issue is the way that, despite a tendency in both the humanities and the social sciences to emphasise interdisciplinarity, relatively little attention has been paid to the interdisciplinary imaginaries that inform both scholarship and practice in these areas, including philosophy of education. Greater attention to these imaginaries would mean tracing and interrogating the manner in which key educational and philosophical images slide across disciplinary registers, theoretical approaches and pedagogical contexts, and exploring both what happens to these images and what work they do in such processes of translation. In this issue, play, animacy, criticality and becoming are just some of the transdisciplinary images whose potential for shifting pedagogical imaginaries are explored. In keeping with the work the contributors undertake in exploring such images, we argue that pedagogical theory and practice is an inherently interdisciplinary terrain where social, affective, historical, political, bodily and material forces meet and intersect. For this very reason, it provides an ideal context within which to assess the critical purchase of the interdisciplinary imaginaries that inform new approaches to feminist theorising.

In recent times, feminist theories of the body have witnessed a shift from discursive perspectives informed by the work of such thinkers as Judith Butler, Susan Bordo and Gayatri Spivak towards a 'new materialism' through which bodies are seen as significant agents whose activities are not entirely inscribed or determined by language. Butler's work, for 
example, depicts processes of materialisation as eminently tied to dominant discursive structures while also claiming that lived bodies are not entirely determined by these structures and therefore can be mobilised to transgress the discursive horizons that they inhabit. For Butler, then, bodies are modalities of engagement with mediating forms of thought, ideas, and concepts that participate in the emergence of matter itself. What is different in more recent formulations of bodies is that materiality is discussed more in terms of an inherently lively 'thingness' (Jane Bennett) or matter-ing (Karen Barad) and less in terms of its being a site of inscription or materialisation. Thinkers such as Elizabeth Grosz and Stacy Alaimo, as well as Barad and Bennett, take up the traditional alignment of (feminine) matter with passive receptivity or inert 'stuff' as opposed to active (masculine) form-giving agency, and ask - as Alaimo puts it - 'How can we think matter as activity rather than passive substance?' (Alaimo 2008, 245). Such a rethinking of matter is urgently required to transform our relations not only to our own (sexuate, raced, diversely abled) bodies but also to the multiple (human and non-human) materialities that constitute and sustain us.

This reorientation of thinking about materiality intersects with feminist pedagogy, which has paid sustained attention to the ways in which educational experiences are shaped not only by the gendering of physical and discursive spaces, but also by the ways in which differing bodies inhabit and encounter one another in those spaces. The intersectionist approach that often characterises such work resonates with the relational ontologies of the 'new materialists'. Thus, Alaimo's 'transcorporeality' (Alaimo 2008, 2010) and Nancy Tuana's 'interactionist ontology' (Tuana 2008) might be read together with Spivak's account of education as a 'mischief' that conducts solidarity across differences (Spivak 2008, 163-164). This in turn brings out the importance of an approach attuned by feminist, queer and critical race theories to new materialist concerns. If human beings no longer are represented in terms of a constitutive nature/culture divide, and instead are re-imagined as emerging within intersecting networks of diverse materialities, then feminist, queer and critical race theorists remind us that, just as 'there is no body as such' but 'only bodies' - 'male and female, black, brown, white, large or small and gradations in between' (Grosz 1994, 19) - so too there is no uniform matter 'as such', but only diversely inflected and intersecting materialities. While 'new materialists' call into question the social constructivism that often informs intersectionist approaches, they also decentre the human in ways that implicitly expand such approaches to include the intersections of human and non-human materialities. This in turn might make us more attentive to the role of non-human materialities in the pedagogical encounter. A number of contributors to this volume foreground the often forgotten or ignored material, architectural and equipmental support of the classroom as well as the ways in which moments of learning can unfold between human and non-human others.

Nonetheless, some of the criticisms of the new materialist approaches might make us pause before adopting a 'new materialist' frame for theorising the pedagogical encounter. On the one hand, such approaches have been criticised for overly attenuating human agency; on the other, in thinking matter as 'agential', they are criticised for projecting a still-too-human conception of action and agency onto the non-human. The 'new materialist' thinkers mentioned here are aware of these risks of perpetuating anthropocentric thinking, even if they tackle them in differing ways. ${ }^{2}$ However, they are unapologetic that their approaches do involve 'attenuating' human agency if by this we mean 
relinquishing the modern western ideal of an entirely autonomous and self-sufficient rational subject. Grosz's 'politics of imperceptibility' (2005), Alaimo's 'trans-corporeality' (2008, 2010), and Bennett's 'distributive agency' (2010) all involve a serious critique of this ideal in ways that mean giving up damaging illusions of control and invulnerability. They invite us not to relinquish but to rethink agency and responsibility. The pedagogical context is a crucial testing ground for this knowingly risky but much needed rethinking, allowing us to attend to its lived implications.

The greater risk facing the new materialist approaches is the readiness with which the images of 'life', 'becoming', and 'active matter' can be re-appropriated by contemporary neoliberal and biopolitical regimes in which everything must be productive such that, as Johanna Oksala puts it, 'We have become entrepreneurs of our own lives, competing in the free market we call society... Our life has become an enterprise that we must lead to success' $(2012,146)$. The images of networks of trans-corporeal, trans-active matter are easily re-captured by a rhetorics of networking in which relations are thoroughly re-instrumentalised. The challenge then is how to re-imagine matter as active and generative in ways that foster non-instrumentalised, ethical relations with diverse bodies and materialities while resisting recuperation by neoliberal networks and flows as well as the productivity required by capitalist imperatives. ${ }^{3}$

In our view, education constitutes a key site for responding to this challenge and thinking through these risks. On the one hand, it is impossible to ignore the ways in which education is permeated by a neoliberal normativity that seeks to micro-manage the lives of children, teachers and parents to ensure they are engaging in the enterprise of their lives in appropriately productive ways. On the other hand, the pedagogical remains, despite it all, a place where risky, unpredictable encounters can unfold with a value that exceeds what is 'useful' or 'productive' within existing norms and modes of being. At the same time, the intrinsic relationality and unequal power relations of the pedagogical scene call on us to resist a romanticisation of the 'risky' and to attend to the distributed responsibilities that characterise relations of care. As both a contested site and a site of contestation, the pedagogical encounter allows us to take up the images offered by the new materialisms - 'becoming', 'life', 'affect' and 'animacy' - and to test their potential and their limits in relation to both transformation and resistance.

By foregrounding a pedagogical context, we also want to draw attention to what is sometimes not so much in focus in 'new materialist' renderings of the body, namely, the sensible aspects of human materiality and the ways in which sensible, bodily forms are generated through unpredictable contact with non-human materialities within a shared environment. That is, we wish to ask how, in these moments of contact between things, the sensations produced in classrooms - the touch of the keyboard, the sweatiness of a hand I'm holding, the smell of perfume, the grooves of the desk - matter to the constitution of the body, its surfaces and borders. In a 2004 essay, Elspeth Probyn discusses the extent to which pedagogical theories informing critical, transformative and feminist education have generally elided the question of 'lived bodies'. That is, while numerous theories abound about the constitution of the body through power, norms and structures of discrimination, little attention is paid to the role played by singular and sensible affects. For Probyn, there seems to be a 'retreat from the experiential body' (23) in these pedagogies. Opening up this pedagogical question means having to posit a different imaginary configuration of the body as one that is rooted in the realm of sensibility 
as well as materiality, in the realm of experience as well as thingness. Such an imaginary can serve to reframe our attention to materiality such that questions of sensibility, affect and experience (Ahmed 2006, 2010) become integral to the formation of materiality. What then comes more sharply into focus is not only the idea that bodies are 'modes not substances', but that there are constellations of affect, sensibility, and lived experiences that are always involved in constituting these modes. This double focus rereads feminist and other transformative pedagogies as practices involved in the unpredictable and continually emerging conditions of teaching, learning and change.

The essays in this issue collectively take up the threads of embodiment, affect and materialism in order to shift the imaginaries through which education is practiced and made intelligible. Moreover, what they make evident is how the complexity and diversity of educational practices actually demand something from philosophy, resisting the notion that the relationship between education and philosophy is simply one of the application of concepts or the instrumentalisation of ideas. Instead, each of the articles here situates itself within the nexus of theory-practice, allowing an open conversation between philosophy and education to develop by generating images that challenge conventional disciplinary borders. Thus, Ada Jaarsma playfully mobilises the image of the 'tomato', as well as her own teaching practice, to open a space for considering the role of design-work in teaching. Drawing on the conjoined lenses of disability studies and Brian Massumi's work on play, this article puts into practice the flexible, inventive thinking that it argues is needed if we are to generate pedagogical encounters that are lively, transformative and inclusive. In so doing, Jaarsma invites us to play with our own teaching repertoires. Such an invitation is taken up in the second article, where Anna Hickey-Moody, Helen Palmer and Esther Sayers explore possibilities for a practice-based arts education that moves across bodies and media to shift dominant representations and re-make images of both bodies and learning. Again, there is a performative element to this piece, as new materialist models of diffractive analysis are themselves diffracted through reflections on practice that animate a more experimental, flexible educational imaginary.

The transformative potential of an aesthetic, visual thinking is demonstrated in the third contribution. In this essay, Alyssa Niccolini explores the rippling effects - and affects - generated by the dismissal of a student-teacher in New York for inviting her students to write a poem on themes including homophobia. Niccolini draws on the teacher's 'autographic' visual representations of the events in question to tease out the multiple ways in which 'affect operates as an animate form of pedagogy' (Niccolini, 2016, 232), exceeding the thematisation of fears and desire, and teaching instead through the ways in which affect works across bodies of all kinds: human and more-than-human, singular and institutional, textual and visual. This role of affective economies within pedagogical contexts is further explored by Aoife Neary in a paper focusing on the experiences of Lesbian, Gay, Bisexual, Transgender and Queer teachers entering into civil partnerships in Ireland. Neary mobilises concepts of affective labour alongside insights from Ahmed to show how a heteronormative orientation towards sexuality is maintained even as it is disrupted by non-linear moments of transgression that open up a queer temporality of change. Ahmed is also a key figure for Cathrine Ryther, who complicates the image of pedagogically desirable emotions by considering the role of hate in pedagogical relations. Ryther takes the reader into uncomfortable affective terrain by confronting us not only with the feelings of hate that can arise within the pedagogical process, but with the image of the body 
that has been 'sealed in' by hate. To respond to such bodies in an ethically responsible and transformative way means being willing to share the world with them, she argues, as well as responding to their need to 'unseal' their skin and re-make their world (Ryther 2016, 276).

That education may be a site - tentative and risky, plural and always in process - for remaking the world in shared and open-ended experiments is a thought that runs through many of these papers, even as they also testify to the ways in which such transformative possibilities can be shut down or contained. Equally, while the unruly encounters of practice often refuse to fit the aspirations of pedagogical theory, these papers testify to the importance of attending to just such unruly moments, where transformative possibilities and re-normalising tendencies can co-habit in unexpected ways. Such attention depends on our ability as educational researchers to live with the vulnerability and absence of autonomy that, as feminist and queer theorists, we are happy to espouse, in order that we do not shut down the specificities and transformative potentialities of practice by deploying concepts like ciphers, and instead allow ourselves to be moved, transported and undone by the vagaries of what happens (to us, and to theory) within the pedagogical encounter. That such encounters demand an ability to live with discomfort is reinforced by Danvers' investigation into the affects that surround the concept and practice of critical thinking. Danvers shows how the ambivalence attendant on 'being critical' for undergraduate students re-emerges in the tensions between the work of Barad and Ahmed, in ways whose significance can only be appreciated once we attend to critical thinking as an affective, embodied practice. Read with Jaarsma, Danvers' article invites us to reflect on the extent to which our own teaching practices reproduce the image of critical thinking as negation and mastery, or re-imagine it as a process of experimental play through which both teachers and students might be more likely to learn how to live with affective ambivalence.

The final paper, by Erica Hagström, takes us back to Massumi's work on the 'animal politics' of education by exploring the pedagogical relation through a human-horse relation. Whereas the image of 'becoming-animal' is usually invoked as metaphor or analogy, here the specificities of a lived human-horse relation are detailed carefully, providing an innovative lens for questioning the human-centredness of educational theory, exploring the power relations of pedagogical encounters, and re-imagining pedagogical becoming as a thoroughly embodied openness to an embodied other. In ways that recall HickeyMoody, Palmer and Sayer's emphasis on becoming as intransitive event, Hagström suggests that focussing on the openness of an unpredictable encounter with a nonhuman other might also help us to attend to the open unpredictability that ought to inhabit all pedagogical encounters. From tomatoes to horses, autographics to sticky affects, the innovative approaches taken by the contributors to this special issue show that explorations of affect, embodiment and materiality also require images that reflect the deep co-implication of thought and action, complicating the relationship between education and philosophy and refusing any fixed hierarchy between them. It is not as if concepts are simply 'used' to explain or to explore pedagogical phenomena; rather these essays demonstrate how conceptualising itself arises as an action that is part of a dialogical movement, allowing pedagogical phenomena to reframe our attention to theory and allowing theory to re-signify and re-animate the educational encounter. In the papers that follow, this entwinement both keeps alive the tensions between thinking 
and doing philosophy and education, and provokes new figurations that enable novel horizons for praxis.

\section{Notes}

1. See the special issue of Gender and Education, 2013 Issue 6: Material Feminisms: New Directions for Education.

2. For example, while Bennett is willing to risk a certain anthropomorphism to displace what she sees as a more dangerous anthropocentrism (Bennett 2010,120), Alaimo notes that the challenge is how we might conceive of nature's agency 'in ways that are neither anthropomorphic, nor reductive, nor silly-seeming' (Alaimo 2008, 245).

3. For this reason, the image of active matter has itself been criticised by thinkers aligned with the 'new materialist' approach - see in particular Colebrook's concerns about 'an always-productive becoming' and her argument that a more resistant figure of matter is found in the inert as that which does not strive to live (Colebrook 2008).

\section{References}

Ahmed, Sara. 2006. Queer Phenomenology, Orientations, Objects, Others. Durham, NC: Duke University Press.

Ahmed, Sara. 2010. The Promise of Happiness. Durham, NC: Duke University Press.

Alaimo, Stacy. 2008. "Trans-Corporeal Feminism and the Ethical Space of Nature." In Material Feminisms, edited by S. Alaimo, and S. Hekman, 237-264. Bloomington, IL: Indiana University Press.

Alaimo, Stacy. 2010. Bodily Natures. Bloomington, IL: Indiana University Press.

Bennett, Jane. 2010. Vibrant Matter. Durham, NC: Duke University Press.

Colebrook, Claire. 2008. "On Not Becoming Man: The Materialist Politics of Unactualized Potential." In Material Feminisms, edited by S. Alaimo and S. Hekman, 52-84. Bloomington, IL: Indiana University Press.

Gatens, Moira. 1996. Imaginary Bodies. London: Routledge.

Grosz, Elizabeth. 1994. Volatile Bodies: Toward a Corporeal Feminism. Bloomington, IL : Indiana University Press.

Grosz, Elizabeth. 2005. Time Travels. Durham, NC: Duke University Press.

Niccolini, Alyssa. 2016. "Animate affects: censorship, reckless pedagogies, and beautiful feelings" Gender and Education 28 (2): 230-249. doi:10.1080/09540253.2015.1121205.

Oksala, Johanna. 2012. Foucault, Politics and Violence. Evanston, IL: Northwestern University Press.

Probyn, Elspeth. 2004. "Teaching Bodies: Affects in the Classroom." Body and Society 10 (4): 21-43.

Ryther, Cathrine. 2016. "On the image of hate in education: desirable emotions, learning, and the visibility of bodies in educational relations" Gender and Education 28 (2): 266-281. doi:10.1080/ 09540253.2015 .1132300 .

Spivak, Gayatri Chakravorty. 2008. Outside in the Teaching Machine. London: Routledge.

Tuana, Nancy. 2008. "Viscous Porosity: Witnessing Katrina." In Material Feminisms, edited by S. Alaimo and S. Hekman, 188-213. Bloomington, IL: Indiana University Press. 